\title{
Analisis Keputusan Pembelian Berbasis Sikap Konsumen
}

\author{
Mar'atush Sholihah' ${ }^{1}$ Ambar Lukitaningsih ${ }^{2}$ Henny Welsa $^{3}$ \\ Universitas Sarjanawiyata Tamansiswa Yogyakarta \\ Email : maratushsalsa@gmail.com
}

\begin{abstract}
This study to determine the significance of the positive influence of research variables. The variables of this study are ease of access, attractiveness of post massage, responsiveness of service, consumer attitudes and purchasing decisions. The population of this research is Azza Wedding wedding package consumers in 2019. The number of samples in this study 100 respondents were determined using the Slovin method for known population numbers, data collection methods using probability methods and sampling techniques using simple random sampling. The data analysis tool uses a questionnaire. For testing instruments using the SPSS 18.0 program with a significance level of 0.05. Data analysis techniques for indicator testing, model fit testing and hypothesis testing using the Smart PLS 3.0 program

The results of this study indicate: 1) ease of access has a positive and significant effect on consumer attitudes, 2) attractiveness of post massage has a positive and significant effect on consumer attitudes, 3) service responsiveness has a positive and not significant effect on consumer attitudes, 4) consumer attitudes have a positive effect and significant on purchasing decisions, 5) ease of access has a positive and significant effect on purchasing decisions, 6) attractiveness of post massage has a positive and not significant effect on purchasing decisions, 7) responsiveness of service has a positive and not significant effect on purchasing decisions, 8) ease of access positive and significant effect on purchasing decisions through consumer attitudes, 9) attractiveness of post massage has a positive and significant effect on purchasing decisions through consumer attitudes, 10) responsiveness of service has a positive and not significant effect on purchasing decisions through attitude consumer.
\end{abstract}

\section{Keywords: ease of access, attractiveness of post massage, responsiveness of service, consumer attitudes and purchasing decisions}

\begin{abstract}
ABSTRAK
Penelitian ini bertujuan untuk mengetahui signifikansi pengaruh positif variabel penelitian. Variabel penelitian ini adalah kemudahan akses, kemenarikan posting massage, daya tanggap pelayanan, sikap konsumen dan keputusan pembelian. Populasi penelitian ini yaitu konsumen paket pernikahan Azza Wedding pada tahun 2019. Jumlah sampel dalam penelitian ini 100 responden ditentukan menggunakan metode slovin untuk jumlah populasi yang sudah diketahui, metode pengumpulan data menggunakan metode probabilitas dan teknik pengambilan sampel menggunakan simple random sampling. Alat analisis data menggunakan kuesioner. Untuk pengujian instrumen menggunakan program
\end{abstract}

Bisman (Bisnis \& Manajemen): The Journal Of Business and Management 
SPSS 18.0 dengan taraf signifikan 0,05. Teknik analisis data untuk uji indikator, uji model fit dan uji hipotesis menggunakan program Smart PLS 3.0

Hasil penelitian ini menunjukkan : 1) kemudahan akses berpengaruh positif dan signifikan terhadap sikap konsumen, 2) kemenarikan posting massage berpengaruh positif dan signifikan terhadap sikap konsumen, 3) daya tanggap pelayanan berpengaruh positif dan tidak signifikan terhadap sikap konsumen, 4) sikap konsumen berpengaruh positif dan signifikan terhadap keputusan pembelian, 5) kemudahan akses berpengaruh positif dan signifikan terhadap keputusan pembelian, 6) kemenarikan posting massage berpengaruh positif dan tidak signifikan terhadap keputusan pembelian, 7) daya tanggap pelayanan berpengaruh positif dan tidak signifikan terhadap keputusan pembelian, 8) kemudahan akses berpengaruh positif dan signifikan terhadap keputusan pembelian melalui sikap konsumen, 9) kemenarikan posting massage berpengaruh positif dan signifikan terhadap keputusan pembelian melalui sikap konsumen, 10) daya tanggap pelayanan berpengaruh positif dan tidak signifikan terhadap keputusan pembelian melalui sikap konsumen.

\section{Kata Kunci: kemudahan akses, kemenarikan posting massage, daya tanggap pelayanan, sikap konsumen dan keputusan pembelian}

\section{PENDUHULUAN}

Media sosial yang populer saat ini untuk berbisnis online adalah Instagram. Berdasarkan data Napoleon.Cat pengguna Instagram di Indonesia pada tahun 2019 mencapai 61,6 juta orang dari berbagai kalangan dan usia. Sebanyak 89 persen penggunanya usia 18 - 34 tahun. Usia tersebut merupakan konsumen potensial yang membutuhkan layanan jasa pernikahan. Melalui media sosial Instagram konsumen mencari informasi terkait kebutuhan pernikahan. Persiapan pernikahan yang diurus sendiri terkadang dapat menimbulkan masalah-masalah yang tidak terduga. Hal ini dikarenakan banyaknya acara dan kebutuhan yang harus diurus sendiri, seperti pertimbangan dalam memilih lokasi, menentukan konsep, manajemen waktu, biaya yang diperlukan dan memilih vendor pernikahan.

Azza Wedding merupakan jasa penyelenggara pernikahan di Yogyakarta, Magelang, Klaten, Purworejo, Solo dan sekitarnya dengan memberikan paket pernikahan terdiri dari dekorasi, rias pengantin, foto, catering, hiburan, pemandu acara (MC) dan tim wedding organizer. Paket pernikahan diberikan untuk memudahkan konsumen dalam menghemat waktu, lebih murah, terkoordinir, dan vendor pernikahan lengkap. Berdasarkan data yang diperoleh dari Marketing Azza Wedding, jumlah paket pernikahan tahun 2019 yang telah dipesan oleh konsumen sejumlah 144 paket pernikahan yang terdiri dari paket ekonomis, standar, hemat, medium, spesial dan komplit.

\section{KAJIAN PUSTAKA}

\section{Sosial Media Marketing}

Media Sosial adalah media yang didesain untuk memudahkan interaksi sosial yang bersifat interaktif (Craig dan Lefebvre, 2011). Kemudian pada

Bisman (Bisnis \& Manajemen): The Journal Of Business and Management 
perkembangannya sosial media banyak digunakan pebisnis untuk memasarkan produknya. Menurut Erlangga (2011) sosial media marketing adalah sebuah bentuk strategi marketing yang digunakan sebagai sarana interaksi dengan aktivitas utama yaitu memasarkan sesuatu (produk, merek, isu, pelayanan dan lain-lain) menggunakan berbagai fasilitas media sosial yang memanfaatkan anggota yang berpartisipasi di media sosial dalam kampanye produknya.

\section{Kemudahan Akses}

Ahmad Pambudi (2014) kemudahan akses adalah kepercayaan seseorang dalam menggunakan suatu sistem akan terbebas dari usaha. Intensitas penggunaan dan interaksi antar user dengan sistem juga dapat menunjukkan kemudahan. Suatu sistem online yang lebih sering digunakan dapat menunjukkan bahwa sistem tersebut lebih dikenal, lebih mudah dioperasikan dan lebih mudah digunakan oleh user. Sistem yang lebih sering digunakan menunjukkan bahwa teknologi tersebut lebih dikenal, lebih mudah dioperasikan, dan lebih mudah digunakan oleh penggunanya. Intensitas merupakan suatu ukuran kekuatan, keadaan tingkatan atau ukuran intens seseorang (Fitriyani, 2014).

\section{Kemenarikan Posting Massage}

Menurut Adi (2013) iklan, posting massage dapat dikatakan menarik apabila isi massage tersebut memiliki kemampuan untuk menarik pasar sasaran dan mampu menarik minat atau follower dalam akun tersebut untuk sekedar berkomentar, biasanya konten berupa berita, informasi atau tips -tips yang bermanfaat yang dapat memunculkan interaksi antar teman atau anggota yang mengikuti account tersebut. Menurut A Shimp (2014) secara umum periklanan dihargai karena dikenal sebagai pelaksana beragam fungsi komunikasi yang penting bagi perusahaan bisnis dan organisasi lainnya sebagai berikut : Informing (member informasi), Persuading (mempersuai), Reminding (mengingatkan), Adding value (memberikan nilai tambah) dan Assisting (pendampingan).

\section{Daya Tanggap Pelayanan}

Menurut Philip Kotler (2012) pelayanan adalah setiap tindakan atau kegiatan yang dapat ditawarkan oleh suatu pihak kepada pihak lain, yang pada dasarnya tidak berwujud dan tidak mengakibatkan kepemilikan apapun. Menurut Philip Kotler (2012) terdapat lima dimensi dari service quality sebagai berikut : Tangible (bukti fisik), Reliability (keandalan), Responsiveness (ketanggapam), Assurance (jaminan) dan Emphaty. Sedangkan menurut Tjiptono (2015) daya tanggap (responsiveness) yaitu kesediaan dan kemampuan penyedia layanan untuk membantu para pelanggan dan merespon permintaan dengan segera.

\section{Sikap Konsumen}

Menurut Philip Kotler (2012) sikap adalah evaluasi, perasaan, kecenderungan seseorang yang relatif konsisten terhadap suatu objek atau gagasan. Sikap menempatkan seseorang kedalam satu pikiran menyukai atau tidak menyukai sesuatu, bergerak mendektai atau menjauhi sesuatu. Sikap seseorang

Bisman (Bisnis \& Manajemen): The Journal Of Business and Management 
terhadap suatu objek adalah perasaan mendukung atau memihak maupun perasaan tidak mendukung atau tidak memihak pada objek tersebut (Azwar, 2012).

\section{Keputusan Pembelian}

Keputusan pembelian adalah suatu proses penyelesaian masalah yang terdiri dari menganalisa kebutuhan, keinginan, pencarian informasi, penilaian sumber-sumber seleksi terhadap alternatif pembelian, keputusan pembelian dan perilaku setelah pembelian (Philip Kotler, 2012). Menurut Philip Kotler (2012) Terdapat lima tahap dalam proses keputusan pembelian adalah sebagai berikut : pengenalan masalah, pencarian informasi, evaluasi alternatif, keputusan pembelian, dan perilaku pasca pembelian.

\section{Kerangka Pikir}

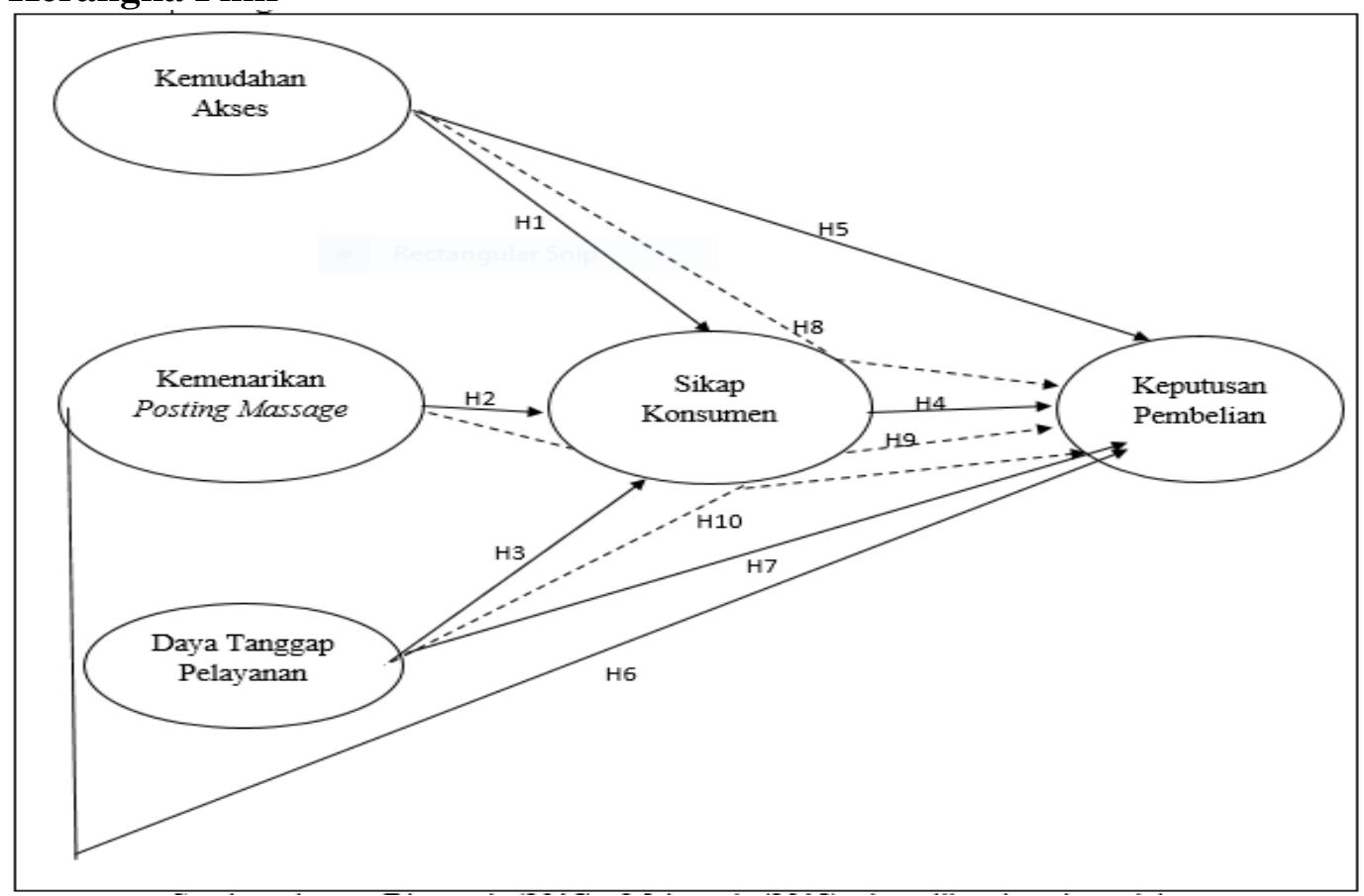

\section{METODE PENELITIAN}

Gambar 1. Kerangka Pikir

\section{Subyek, Populasi dan Sampel}

Subyek pada penelitian ini adalah konsumen paket pernikahan Azza Wedding pada tahun 2019. Penelitian ini menggunakan metode kuantitatif. Populasi pada penelitian ini adalah seluruh konsumen paket pernikahan Azza Wedding pada tahun 2019 yang berjumlah 144 orang. Dalam penelitian ini jumlah populasi sudah diketahui sehingga menggunakan metode slovin. $n=\frac{\mathrm{N}}{1+\mathrm{Ne}^{2}}$. Dimana : $\mathrm{n}=$ ukuran sampel, $\mathrm{N}=$ populasi dan $\mathrm{E}=$ nilai presisi (misalnya tingkat kepercayaan $95 \%$, maka $\mathrm{e}=0,05)$. pada penelitian ini adalah sebagai berikut $n=\frac{144}{1+144.0,05^{2}}=98,88$ dibulatkan menjadi 100 responden.

\section{Jenis dan Metode Pengumpulan Data}

Penelitian ini menggunakan jenis sumber data primer dan data sekunder. Data primer diperoleh secara langsung melalui kuesioner dengan cara penyebaran

Bisman (Bisnis \& Manajemen): The Journal Of Business and Management 
daftar pertanyaan kepada responden tentang kemudahan akses, kemenarikan posting massage, daya tanggap pelayanan, sikap konsumen dan keputusan pembelian pada responden paket pernikahan Azza Wedding tahun 2019. Data sekunder diperoleh dari data penjualan Azza Wedding tahun 2019. Dalam penelitian ini metode pengumpulan data menggunakan metode probabilitas dan teknik pengambilan sampel menggunakan simple random sampling.

\section{Uji Instrumen}

Untuk menguji apakah daftar kuesioner yang dibuat berdasarkan indikator indikator yang ada pada setiap variabel penelitian, maka digunakan alat uji yaitu uji validitas dan uji reliabilitas dengan menggunakan program SPSS versi 18.0 dengan tingkat signifikansi 0,05 . Jika $\mathrm{r}$ hitung $\geq \mathrm{r}$ tabel maka instrumen atau item - item pernyataan berkorelasi signifikan terhadap skor total, maka dinyatakan valid. Sedangkan jika $r$ hitung $<\mathrm{r}$ tabel maka instrumen pernyataan tidak berkorelasi signifikan terhadap total skor, maka dinyatakan tidak valid (Wiyono, 2011). Untuk menguji reliabilitas pada penelitian ini menggunakan metode Cronbach's. Pengujian reliabilitas menggunakan Cronbach's : a.) jika Cronbach's alpha > 0,7 maka variabel tersebut reliable dan b. jika Cronbach's alpha $<0,7$ maka variabel tersebut tidak reliabel.

\section{Teknik Analisis Data}

Penelitian ini menggunakan teknik analisis deskriptif yaitu Structural Equation Modeling (SEM) dengan menggunakan alat analisis Partial Least Square (PLS) yaitu SEM berbasis variance dengan sofware SmartPLS. Tahap pengujian sebagai berikut : uji indikator, uji model fit dan uji hipotesis. Tahap selanjutnya untuk mengetahui seberapa besar peran variabel intervening pada penelitian ini menggunakan uji sobel test.

\section{PEMBAHASAN DAN HASIL}

Hasil penelitian ini dapat diketahui melalui analisis inferensial yang dilakukan berdasarkan hasil uji model struktural dan uji hipotesis adalah sebagai berikut. 


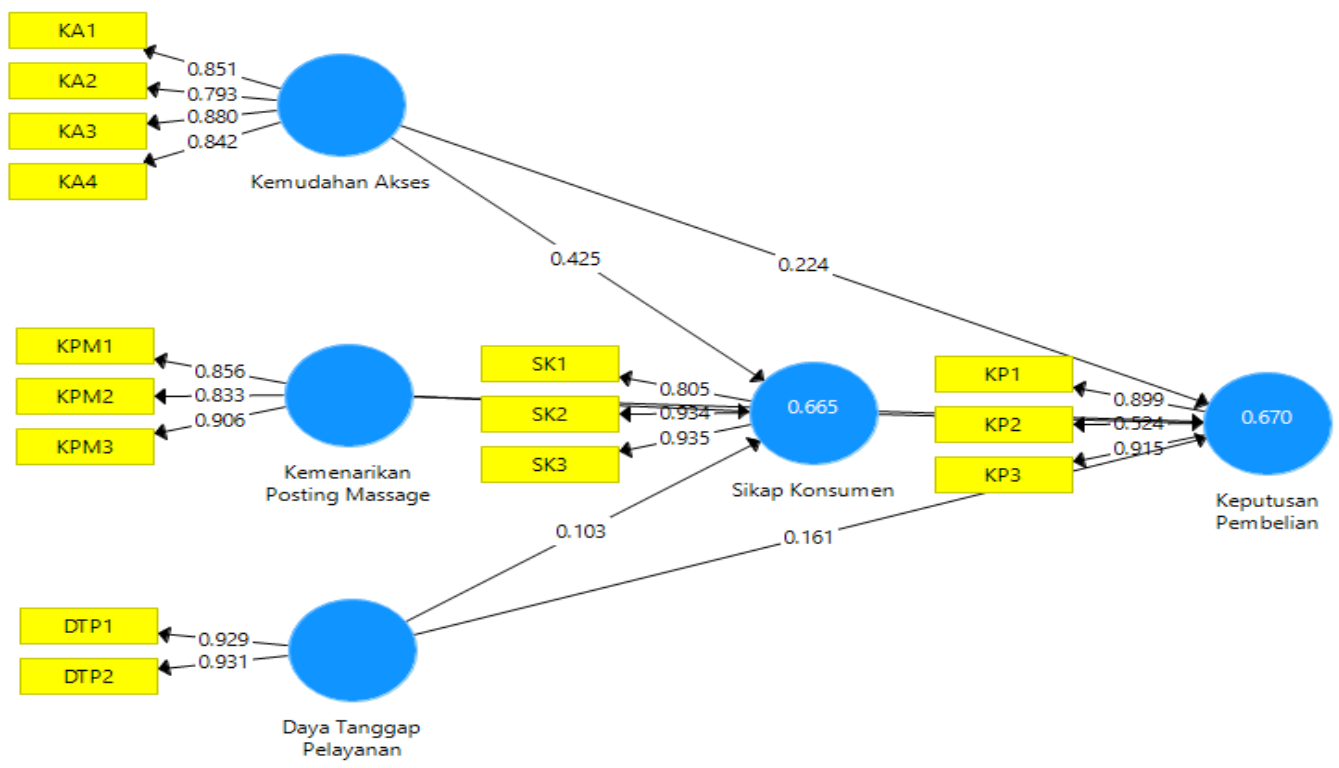

Gambar 2 Model Setelah Uji Indikator

Tabel 1 Hasil Uji Hipotesis

\begin{tabular}{|c|c|c|c|c|}
\hline & Hipotesis & $\begin{array}{l}\text { Koefisien } \\
\text { Parameter }\end{array}$ & P Values & Kesimpulan \\
\hline H1 & $\begin{array}{l}\text { Kemudahan akses berpengaruh positif terhadap } \\
\text { sikap konsumen }\end{array}$ & 0,390 & 0,001 & Terbukti \\
\hline H2 & $\begin{array}{l}\text { Kemenarikan posting massage berpengaruh } \\
\text { positif terhadap sikap konsumen }\end{array}$ & 0,397 & 0,005 & Terbukti \\
\hline H3 & $\begin{array}{l}\text { Daya tanggap pelayanan berpengaruh positif } \\
\text { terhadap sikap konsumen }\end{array}$ & 0,116 & 0,368 & $\begin{array}{l}\text { Tidak } \\
\text { Terbukti }\end{array}$ \\
\hline H4 & $\begin{array}{l}\text { Sikap konsumen berpengaruh positif terhadap } \\
\text { keputusan pembelian }\end{array}$ & 0,515 & 0,000 & Terbukti \\
\hline H5 & $\begin{array}{l}\text { Kemudahan akses berpengaruh positif terhadap } \\
\text { keputusan pembelian }\end{array}$ & 0,238 & 0,023 & Terbukti \\
\hline H6 & $\begin{array}{l}\text { Kemenarikan posting massage berpengaruh } \\
\text { positif terhadap keputusan pembelian }\end{array}$ & 0,055 & 0,600 & $\begin{array}{l}\text { Tidak } \\
\text { Terbukti }\end{array}$ \\
\hline H7 & $\begin{array}{l}\text { Daya tanggap pelayanan berpengaruh positif } \\
\text { terhadap keputusan pembelian }\end{array}$ & 0,114 & 0,225 & $\begin{array}{l}\text { Tidak } \\
\text { Terbukti }\end{array}$ \\
\hline H8 & $\begin{array}{l}\text { Kemudahan akses berpengaruh positif terhadap } \\
\text { keputusan pembelian melalui sikap konsumen }\end{array}$ & 0,201 & 0,002 & Terbukti \\
\hline H9 & $\begin{array}{l}\text { Kemenarikan posting massage berpengaruh } \\
\text { positif terhadap keputusan pembelian melalui } \\
\text { sikap konsumen }\end{array}$ & 0,205 & 0,021 & Terbukti \\
\hline H10 & $\begin{array}{l}\text { Daya tanggap pelayanan berpengaruh positif } \\
\text { terhadap keputusan pembelian melalui sikap } \\
\text { konsumen }\end{array}$ & 0,060 & 0,393 & $\begin{array}{l}\text { Tidak } \\
\text { Terbukti }\end{array}$ \\
\hline
\end{tabular}

Sumber : Data Primer, diolah 2020

Dari Tabel 1 hasil uji hipotesis diatas dapat diketahui sebagai berikut.

H1: Kemudahan akses berpengaruh positif dan signifikan terhadap sikap konsumen

Berdasarkan nilai pengujian hipotesis H1 nilai koefisien parameter 0,390.

Diketahui bahwa kemudahan akses (KA) memiliki pengaruh positif terhadap

Bisman (Bisnis \& Manajemen): The Journal Of Business and Management 
sikap konsumen (SK), sedangkan P-Value diperoleh nilai 0,001 $(<0,05)$. Hal ini menunjukkan bahwa kemudahan akses (KA) berpengaruh signifikan terhadap sikap konsumen (SK). Dengan demikian dapat disimpulkan bahwa hipotesis kesatu, "terbukti".

H2: Kemenarikan posting massage berpengaruh positif dan signifikan terhadap sikap konsumen

Berdasarkan nilai pengujian hipotesis $\mathrm{H} 2$ nilai koefisien parameter 0,397 Diketahui bahwa kemenarikan posting massage (KPM) memiliki pengaruh positif terhadap sikap konsumen (SK), sedangkan P-Value diperoleh nilai 0,005 ( < 0,05). Hal ini menunjukkan bahwa kemenarikan posting massage (KPM) berpengaruh signifikan terhadap sikap konsumen (SK). Dengan demikian dapat disimpulkan bahwa hipotesis kedua "terbukti".

H3 : Daya tanggap pelayanan berpengaruh positif dan signifikan terhadap sikap konsumen

Berdasarkan nilai pengujian hipotesis $\mathrm{H} 3$ nilai koefisien parameter 0,116. Diketahui bahwa daya tanggap pelayanan (DTP) memiliki pengaruh positif terhadap sikap konsumen (SK), sedangkan P-Value diperoleh nilai 0,368 $(>0,05)$. Hal ini menunjukkan bahwa daya tanggap pelayanan (DTP) berpengaruh tidak signifikan terhadap sikap konsumen (SK). Dengan demikian dapat disimpulkan bahwa hipotesis ketiga "tidak terbukti".

H4 : Sikap konsumen berpengaruh positif dan signifikan terhadap keputusan pembelian

Berdasarkan nilai pengujian hipotesis $\mathrm{H} 4$ nilai koefisien parameter 0,515 Diketahui bahwa sikap konsumen (SK) memiliki pengaruh positif terhadap keputusan pembelian (KP), sedangkan P-Value diperoleh nilai 0,000 $(<0,05)$. Hal ini menunjukkan bahwa sikap konsumen (SK) berpengaruh signifikan terhadap keputusan pembelian (KP). Dengan demikian dapat disimpulkan bahwa hipotesis keempat "terbukti".

H5 : Kemudahan akses berpengaruh positif dan signifikan terhadap keputusan pembelian

Berdasarkan nilai pengujian hipotesis H5 nilai koefisien parameter 0,238. Diketahui bahwa kemudahan akses (KA) memiliki pengaruh positif terhadap keputusan pembelian (KP), sedangkan P-Value diperoleh nilai 0,023 $(<0,05)$. Hal ini menunjukkan bahwa kemudahan akses (KA) berpengaruh signifikan terhadap keputusan pembelian (KP). Dengan demikian dapat disimpulkan bahwa hipotesis kelima, "terbukti".

H6 : Kemenarikan posting massage berpengaruh positif dan signifikan terhadap keputusan pembelian

Berdasarkan nilai pengujian hipotesis H6 nilai koefisien parameter 0,055. Diketahui bahwa kemenarikan posting massage (KPM) memiliki pengaruh positif terhadap keputusan pembelian (KP), sedangkan P-Value diperoleh nilai 0,600 $(>0,05)$. Hal ini menunjukkan bahwa kemenarikan posting massage (KPM) berpengaruh tidak signifikan terhadap keputusan pembelian (KP). Dengan demikian dapat disimpulkan bahwa hipotesis keenam "tidak terbukti".

H7 : Daya tanggap pelayanan berpengaruh positif dan signifikan terhadap keputusan pembelian

Bisman (Bisnis \& Manajemen): The Journal Of Business and Management 
Berdasarkan nilai pengujian hipotesis $\mathrm{H} 7$ nilai koefisien parameter 0,114 . Diketahui bahwa daya tanggap pelayanan (DTP) memiliki pengaruh positif terhadap keputusan pembelian (KP), sedangkan P-Value diperoleh nilai 0,225 $(>0,05)$. Hal ini menunjukkan bahwa daya tanggap pelayanan (DTP) berpengaruh tidak signifikan terhadap keputusan pembelian (KP). Dengan demikian dapat disimpulkan bahwa hipotesis ketujuh "tidak terbukti".

H8 : Kemudahan akses berpengaruh positif terhadap keputusan pembelian melalui sikap konsumen

Berdasarkan nilai pengujian hipotesis $\mathrm{H} 8$ nilai koefisien parameter 0,201. Diketahui bahwa kemudahan akses (KA) memiliki pengaruh positif terhadap keputusan pembelian (KP) melalui sikap konsumen (SK), sedangkan P-Value diperoleh nilai 0,002 $(<0,05)$. Hal ini menunjukkan bahwa kemudahan akses (KA) berpengaruh signifikan terhadap keputusan pembelian (KP) melalui sikap konsumen (SK). Dengan demikian dapat disimpulkan bahwa hipotesis kedelapan "terbukti".

H9 : Kemenarikan posting massage berpengaruh positif terhadap keputusan pembelian melalui sikap konsumen

Berdasarkan nilai pengujian hipotesis $\mathrm{H} 9$ nilai koefisien parameter 0,205.

Diketahui bahwa kemenarikan posting massage (KPM) memiliki pengaruh positif terhadap keputusan pembelian (KP) melalui sikap konsumen (SK), sedangkan PValue diperoleh nilai 0,021 $(<0,05)$. Hal ini menunjukkan bahwa kemenarikan posting massage (KPM) berpengaruh signifikan terhadap keputusan pembelian (KP) melalui sikap konsumen (SK). Dengan demikian dapat disimpulkan bahwa hipotesis kesembilan "terbukti".

H10 : Daya tanggap pelayanan berpengaruh positif terhadap keputusan pembelian melalui sikap konsumen

Berdasarkan nilai pengujian hipotesis $\mathrm{H} 10$ nilai koefisien parameter 0,060. Diketahui bahwa daya tanggap pelayanan (DTP) memiliki pengaruh positif terhadap keputusan pembelian (KP) melalui sikap konsumen (SK), sedangkan PValue diperoleh nilai $0,393(>0,05)$. Hal ini menunjukkan bahwa daya tanggap pelayanan (DTP) berpengaruh signifikan terhadap keputusan pembelian (KP) melalui sikap konsumen (SK). Dengan demikian dapat disimpulkan bahwa hipotesis kesepuluh "tidak terbukti".

\section{KESIMPULAN DAN SARAN \\ Kesimpulan}

Berdasarkan hasil penelitian pada konsumen Azza Wedding yang memilih paket pernikahan Azza Wedding berkaitan dengan penelitian ini yang berjudul "Analisis Keputusan Pembelian Berbasis Sikap Konsumen" dengan variabel kemudahan akses, kemenarikan posting massage, daya tanggap pelayanan, sikap konsumen dan keputusan pembelian dapat disimpulkan sebagai berikut. Kemudahan akses berpengaruh positif dan signifikan terhadap sikap konsumen, kemenarikan posting massage berpengaruh positif dan signifikan terhadap sikap konsumen, daya tanggap pelayanan berpengaruh positif dan tidak signifikan terhadap sikap konsumen, sikap konsumen berpengaruh positif dan signifikan terhadap keputusan pembelian, kemudahan akses berpengaruh positif dan

Bisman (Bisnis \& Manajemen): The Journal Of Business and Management 
signifikan terhadap keputusan pembelian, kemenarikan posting massage berpengaruh positif dan tidak signifikan terhadap keputusan pembelian, daya tanggap pelayanan berpengaruh positif dan tidak signifikan terhadap keputusan pembelian, kemudahan akses berpengaruh positif dan signifikan terhadap keputusan pembelian melalui sikap konsumen, kemenarikan posting massage berpengaruh positif dan signifikan terhadap keputusan pembelian melalui sikap konsumen, daya tanggap pelayanan berpengaruh positif dan tidak signifikan terhadap keputusan pembelian melalui sikap konsumen.

\section{Saran}

Berdasarkan hasil penelitian pada konsumen Azza Wedding yang memilih paket pernikahan Azza Wedding, maka penulis memberikan saran sebagai berikut.

Bagi Perusahaan : 1.) Azza Wedding memberikan pelayanan yang cepat dan tanggap dalam melayani konsumen. 2.) Azza Wedding meningkatkan kemenarikan posting massage pada Instagram dan Website untuk memberikan informasi paket pernikahan yang lebih detail. 3.) Azza Wedding meningkatkan pengecekan (Direct Massage) pada Instagram guna melayani konsumen dengan fast respon. 4.) Azza Wedding meningkatkan promosi melalui media online dengan menampilkan event yang sudah berhasil dihandel oleh Azza Wedding dan mengundang konsumen untuk menghadiri event wedding yang dihandel oleh Azza Wedding guna konsumen yakin dengan pelayanan Azza Wedding sebelum memutuskan untuk booking di Azza Wedding.

Bagi peneliti selanjutnya perlu melakukan penelitian yang sama dengan memperbanyak jumlah sampel dan menambah variabel lainnya selain kemudahan akses, kemenarikan posting massage, daya tanggap pelayanan, dan sikap konsumen terhadap keputusan pembelian, sehingga diharapkan akan memperoleh hasil yang lebih sempurna. 


\section{DAFTAR PUSTAKA}

Ahmad Tarmizi, 2017. Analisis Sikap Konsumen Terhadap Keputusan Pembelian Produk Sepeda Motor Honda Merek Vario Pada Pd. Daya Motor Sungai Bahar Muaro Jambi. Ekonomis : Jurnal Of Economics And Business. Vol.1 No.1 September 2017

A. Shimp, Terence. 2014. Komunikasi Pemasaran Terpadu dalam periklanan dan Promosi. Jakarta : Salemba Empat.

Chen Lou,Shupei Yuan. 2019. Influencer Marketing: How Message Value And Credibility Affect Consumer Trust Of Branded Content On Social Media. Journal Of Interactive Advertising. Vol 19,2019 Issue 1.

Davis,Gordon B. 2013. Kerangka Dasar Sistem Informasi Manajemen. Palembang: Maxikom.

Fandy Tjiptono, 2015. Service quality and Satisfaction, Edisi Ke 4. Yogyakarta : Andi Offset

Ghasem Zarei, Bagher Asgarnezhad., Nasim Noroozi. 2019. The Effect Of Internet Service Quality On Consumers' Purchase Behavior: The Role Of Satisfaction, Attitude, And Purchase Intention. Pages 197-220 | Published Online: 02 April. Journal Of Internet Commerce, Taylor And Francis Online

Kamaruddin, Ahmad. 2013. Akuntansi Manajemen: Dasar-Dasar Konsep Biaya dan Pengambilan Keputusan. Edisi Revisi. Jakarta: Rajawali Pers.

Kotler, Philip and Keller. 2013. Manajemen Pemasaran, Edisi 13, Erlangga.

Lay, Melani Shenna. 2019. The Influence Of Perceived Usefulnes, Perceived Ease Of Use, And Perceived Trust Toward Intention To Adopt Mediated By Attitude Of Linkaja Mobile Payment In Surabaya. Undergraduate Thesis, Widya Mandala Catholic University Surabaya.

Nam-Hyun Um, 2019. Antecedents And Consequences Of Consumers' Attitude Toward Social Commerce Sites, Taylor Francis Online, Journal Of Promotion, Vol 25.

Nindy Riska A, 2017. Pengaruh Kemudahan Akses Dan Diskon Terhadap Keputusan Pembelian Pada Situs Online Tiket.Com. Administrasi Bisnis, Fakultas Ilmu Sosial Dan Ilmu Politik, Universitas Diponegoro.

Nurani Melawati, Henny Welsa. 2018. Pengaruh Kemudahan Dalam Akses, Kemenarikan Posting Massage, Daya Tanggap Pelayanan Terhadap Sikap Konsumen Pada Keputusan Pembelian Online Shop Instagram (Studi Kasus Pada Mahasiswa Yogyakarta). Jurnal Upajiwa Dewantara, Vol 2 No 1. April

Ramadhan Fathi, Edriana Pangestuti. 2018. Pengaruh Sikap Konsumen Terhadap Keputusan Pembelian Produk Ekolabel (Studi Pada Produk Pt Ultrajaya). Jurnal Administrasi Bisnis (Jab). Universitas Brawijaya. Vol. 57 No. 1 April

Reza Arif, 2018. Pengaruh Kepercayaan, Kemudahan Dan Persepsi Risiko Terhadap Keputusan Pembelian Jasa Gojek Di Kota Semarang Yang Dimediasi Minat Beli Sebagai Variabel Intervening. Universitas Diponegoro.

Bisman (Bisnis \& Manajemen): The Journal Of Business and Management 
Rifqi Nugrogo, 2013. Analisis Faktor - Faktor Yang Mempengaruhi Keputusan Pembelian Dengan Sistem Pre Order Secara Online (Studi Kasus Pada Online Shop Chopper Jersey). Fakultas Ekonomi dan Bisnis. Universitas Diponegoro.

Riswanti, 2015. Analisis Pengaruh Kemenarikan Posting Message, Daya Tanggap Pelayanan Dan Kemudahan Dalam Akses Terhadap Sikap Konsumen Pada Keputusan Pembelian (Studi Kasus Online Shop Bungas Bags), Univ Diponegoro Ekonomi Dan Bisnis

Selli Nisrina Faradila, 2016. Analisis Pengaruh Persepsi Kemudahan Penggunaan Dan Persepsi Manfaat Terhadap Minat Beli Dengan Kepercayaan Sebagai Variabel Intervening (Studi Pada Pengunjung Toko Online Berrybenka.Com). Universitas Diponegoro Ekonomi Dan Bisnis

Setiadi Nugroho J. 2015. Perilaku Konsumen. Jakarta : Kencana Prenada Group Sugiyono, 2015. Metode Penelitian Bisnis. Bandung : CV. Alfabeta

Suleman, D., Ali, H., Nusraningrum, D., \& Ali, M. M. 2019. Perceived Ease Of Use, Trust And Risk Toward Attitude And Intention In Shopping For Online Fashion Products In Indonesia. Archives Of Business Research, 7(4), 240-253.

Wiyono, Gendro. 2011. Merancang Penelitian Bisnis dengan alat Analisis, SPSS 17.0 dan Smart PLS, Yogyakarta : UPP STIM YKPN 